\title{
Video Production: Getting Started ${ }^{1}$
}

\author{
Ricky Telg and Peyton Beattie ${ }^{2}$
}

This publication about getting started in video production is the first of a four-part series on developing effective video production practices. This series also covers scriptwriting, video equipment and shot composition, and video editing.

\section{Introduction}

Consumers, who would not have been able to shoot and edit their own videos just a decade ago, are now doing so with relative ease, thanks to increasingly affordable video-capable cameras and video editing software packages, coupled with the rise of online video hosting services such as YouTube and Vimeo. Today, we post our videos on the Web so that friends and family can see them, we capture news events and distribute them online to television stations or networks that have websites, and we can shoot video "in the field" and bring the "field" back to the classrooms.

With its ability to combine sound and moving pictures, video is a powerful communication medium and can be extremely effective for delivering information. As a result, video's use is widespread, ranging from television news to entertainment to education. However, a person who has never produced a video program needs to understand the video production process. Prepared with this understanding, you will likely find that video production is a fun process that can draw together a group of novice video producers. The information provided in this publication will assist you in developing video productions.

\section{Is a video production right for you?}

Before you begin planning the initial steps for a video program, you first need to decide whethervideo is right for the project. Certainly, most would agree that one good reason to do a video is if the subject matter is eye-catching and interesting. However, deliberate consideration of some key issues before beginning the video production process will serve you well:

Video is the medium to show motion. If the content does not lend itself to movement or motion, you may wish to use some other medium such as print (handbooks, brochures, newsletters), photography, or audio. It is best to use video when motion is involved, for example, to demonstrate a skill, such as how to shoe a horse, how to drive a tractor, how to shoot photographs.

Consider how long the video's content will be relevant. If the information in the video will be out of date soon, then consider carefullywhether video is your best option. It may take a lot of time and effort to produce a quality video program. Will it be worth the effort to produce a video if the information is outdated before you arefinished?

Consider how long it will take to produce the video. Video production can be a lengthy process. It is not unusual for a project to take several weeks or months from concept to completion. If you need a program relatively soon and have not begun the production process, the video may be difficult to complete in your timeframe.

1. This document is WC123, one of a series of the Department of Agricultural Education and Communication, UF/IFAS Extension. Original publication date June 2012. Revised June 2021. Visit the EDIS website at https://edis.ifas.ufl.edu for the currently supported version of this publication.

2. Ricky Telg, professor, Department of Agricultural Education and Communication; and Peyton Beattie, doctoral student; Department of Agricultural Education and Communication; UF/IFAS Extension, Gainesville, FL 32611.

The Institute of Food and Agricultural Sciences (IFAS) is an Equal Opportunity Institution authorized to provide research, educational information and other services

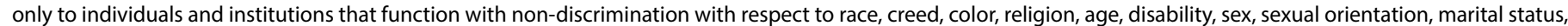

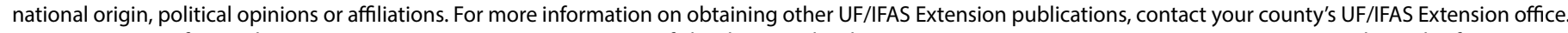
U.S. Department of Agriculture, UF/IFAS Extension Service, University of Florida, IFAS, Florida A \& M University Cooperative Extension Program, and Boards of County Commissioners Cooperating. Nick T. Place, dean for UF/IFAS Extension. 


\section{The Video Production Process}

\section{Audience and Program Analysis}

During this phase, you begin with an idea for the program and determine your audience. Most useful video production ideas are developed for a specific audience. In this step, you should try to identify as many characteristics of your audience as possible, such as the audience members' age, education level, economic status, and values.

How will you develop your video in order to engage the interests of your audience? For example, a video on the importance of dairy products in a person's diet will be a lot different depending on the audience's characteristics; an informational dairy video targeted for children will be considerably different from one targeted for senior adults.

Not only do you need to know your audience's characteristics, but you also need to know what message you want to get across and how you plan to do that. This is the "program analysis" part of this phase. Strategic planning issues such as how much you have to spend (budget), what shooting locations will be involved, the deadline for getting the video produced, who will be involved in the production, and what equipment will be used all must be determined before moving forward.

\section{Preproduction}

During this phase, in-depth research is conducted on the topic that will be covered in the video. A basic content outline follows. Then, begin the writing of a script and storyboard (or shot outline). Scriptwriting, the second publication in this series, provides detail in this regard.

\section{Production}

During this step, crew assignments are made, video shooting locations are scouted, and the actual video shooting takes place. The production phase is only a small part of the "big picture"; a lot of preliminary planning takes place before any footage is shot.

\section{Postproduction}

In postproduction, the video editing and audio editing shape the material received from the production team. Here, video and audio sound effects are added. The release version of the program is duplicated and distributed as a DVD, vodcast (user-subscribed on-demand video podcast), or online Web video.

\section{Additional Information}

Marsh, C., Guth, D.W., \& Short, B.P. (2005). Strategic writing: Multimedia writing for public relations, advertising, sales and marketing. Boston, MA: Pearson Education.

Telg, R. (2004). Producing an educational video. Accessed October 23, 2010. https://edis.ifas.ufl.edu/publication/ WC024

Telg, R. (2004). Producing your own video program. Accessed October 23, 2010. https://edis.ifas.ufl.edu/ publication/WC022

Telg, R. \& Irani, T.A. (2012). Agricultural communications in action: A hands-on approach. Delmar: Clifton Park, NY. 